\title{
Familial occipital and nervus intermedius neuralgia in a Swiss family
}

\author{
Franz Riederer • Peter S. Sándor • \\ Michael Linnebank • Dominik A. Ettlin
}

Received: 21 January 2010/ Accepted: 8 March 2010/Published online: 28 March 2010

(C) Springer-Verlag 2010

\begin{abstract}
Familial trigeminal neuralgia has been reported in $1-2 \%$ of cases consistent with an autosomal dominant inheritance. We present a Swiss family with several members suffering from occipital and nervus intermedius neuralgia alone or in combination. We suggest that peripheral sensory anastomoses or central convergence of afferent pathways could explain neuralgia affecting two cranial nerves. The pedigree has two main characteristics: (1) affected individuals in two generations and (2) in the first generation the father is affected, in the second generation all women are affected, and none of the men. This is suggestive of an X-linked dominant or an autosomal dominant mode of inheritance.
\end{abstract}

Keywords Familial - Genetic - Occipital neuralgia ·

Nervus intermedius neuralgia

\section{Background}

Most cranial neuralgias occur sporadically, although familial cases have been described. Familial trigeminal neuralgia (TN) has been reported in $1-2 \%$ of cases consistent with an autosomal dominant inheritance $[1,2]$. In some of the affected families an association with autosomal

F. Riederer · P. S. Sándor · M. Linnebank

Department of Neurology, University Hospital Zurich,

Zurich, Switzerland

F. Riederer · D. A. Ettlin ( ()

Clinic for Masticatory Disorders, Removable Prosthodontics and Special Care Dentistry, Center for Dental and Oral Medicine and Cranio-maxillofacial Surgery, University of Zurich,

Plattenstrasse 11, 8032 Zurich, Switzerland

e-mail: dominik.ettlin@zzmk.uzh.ch dominant Charcot-Marie-Tooth disease (hereditary sensorimotor polyneuropathy type 1 with demyelination) has been described $[3,4]$. Co-occurrence of familial $\mathrm{TN}$ and other cranial nerve disorders have been reported, for instance with contralateral hemifacial spasm [5]. In 1979 Knuckey and Gubbay [6] published a family where the grandfather suffered from trigeminal neuralgia, his son from trigeminal and glossopharyngeal neuralgia and his granddaughter from glossopharyngeal neuralgia. We present a Swiss family of which several members experienced occipital and nervus intermedius neuralgia (alone or in combination). Some additionally suffered from somnambulism, or migraine. To the best of our knowledge no cases of familial occipital or nervus intermedius neuralgia have been published.

\section{Case reports}

Case 1 is the index patient presenting for cranial and ear pain at the Pain Clinic of the Center for Dental and Oral Medicine, University of Zurich. Two of her sisters (cases 2 and 3) were seen during a pain-free interval. All agreed to a neurological exam at the Neurological Outpatient Clinic, University Hospital, Zurich. The pedigree of this family is shown in Fig. 1.

\section{Case 1: F1947}

A 61-year-old woman was seen in our pain clinic for recurrent lancinating pain deep in her right ear and parietooccipital region. She dated the first bout of deep lancinating right ear pain back to when she was 22 years old. An earnose-throat exam revealed no abnormalities. After a few days this initial pain radiated to the right parieto-occipital 
Fig. 1 Pedigree of a Swiss family with cranial neuralgia (vertical lines), somnambulism (grey background) and migraine (horizontal lines). One or more of these conditions are overlaid on circles (females, $F$ ) and squares (males, M). F1947 means: female, born in 1947. Clinical details are given in the text
Neuralgia

Migraine

Somnambulism

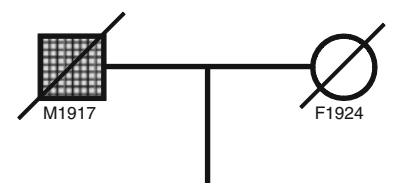

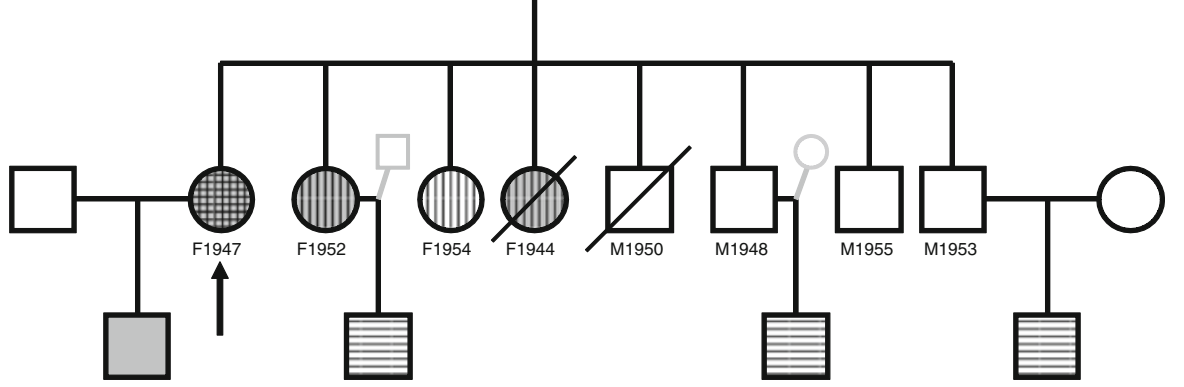

region and jaw consisting of a series of stabs, lasting typically a few seconds and occurring several times per day. After a few weeks the pain disappeared and the patient did not experience a similar episode until the age of 37 . Since then she has been suffering from recurrent pain episodes deep in her right ear and the parieto-occipital region which typically last for several weeks, with an average of two to eight attacks per day. Pain-free intervals last between 3 and 12 months. Attacks can be triggered by light touch and cold stimuli to the right cheek and parieto-occipital region. They are not accompanied by trigemino-autonomic signs such as conjunctival injection, tearing, nasal congestion and no circadian pattern has been observed. The neurological exam was normal apart from tenderness over the right occipital region. No abnormality of the cervical spine was found. An MRI of the brain with contrast agent including MR-angiography showed hypoplastic vertebral and basilar arteries with dominant collateralisation of the posterior territories from the carotid arteries as a normal variant. Carbamazepine $400-600 \mathrm{mg} /$ day did not relieve symptoms sufficiently; clonazepam and metamizole were ineffective. The patient and both, her father and her son suffered from somnambulism during childhood.

In addition, for several years the patient had suffered from migraine without aura fulfilling ICHD-II (International Classification of Headache Disorders, second edition) criteria [7] occurring two to three times per month. Other noteworthy morbidities include diverticulitis, duodenal ulcer and nephrolithiasis.

\section{Case 2: F1952}

The 57-year-old sister of cases 1 and 3 first suffered from a right cranial neuralgia about one year ago. Shortly after recovery from a common cold, she experienced a sudden lancinating pain deep in her right ear that recurred several times, with pain-free intervals. After two more days, this ear pain was followed by recurrent "shock-like" pains in the right occipital region, temple and frontal region radiating into the right jaw. These very painful "shocks" were accompanied by ipsilateral facial tics and occurred several times a day without circadian pattern. There were no evident mechanical triggers and no trigemino-autonomous symptoms were reported. Mefenamic acid $500 \mathrm{mg}$ every $6 \mathrm{~h}$ did not result in significant relief. By the end of three more days all her pains subsided spontaneously without recurring ever since.

The patient also suffered from occasional moderate headaches, yet without accompanying symptoms except for a single headache with unilateral pulsating pain associated with nausea that occurred several years ago. During childhood she had suffered from somnambulism. Otherwise her medical history was unremarkable and the neurological exam was normal.

\section{Case 3: F1954}

The 55-year-old sister of cases 1 and 2 had been suffering from recurrent facial neuralgia for 10 years. Bouts usually lasting for several days or weeks had been occurring once or twice per year, particularly in autumn. She then suffered from severe shock-like pain in the right occipito-parietal region that she compares to "labour-pain". At symptom onset she also suffered from stabbing pain in her right ear. These attacks occurred every few minutes without any identifiable trigger. Between attacks she was pain-free but anticipation of the next attack made her feel anxious. The patient occasionally took paracetamol $500 \mathrm{mg} /$ day without 
significant improvement. Application of "Chinese oil" to the right occipital region caused a local burning, but also relieved the pain to some extent. The patient suffered from moderate holocranial headache without accompanying symptoms about once a year. She was treated for osteoporosis (alendronic acid, calcium carbonate and vitamin D3); otherwise her medical history was unremarkable and the neurological exam was normal.

\section{Family history}

Family history was reported by cases $1-3$. The patients' father (M1917) had suffered from somnambulism until young adulthood and from migraine until the age of 55 . When he was 60 years old, post-herpetic neuralgia developed after left-sided ophthalmic herpes zoster infection. He also suffered from recurrent lancinating occipital and temporal pain. Apart from mild diabetes he was healthy until old age. He died from an intracranial bleeding at the age of 75 .

The patients' mother (F1924) was free of any pain disorders.

One other sister (F1944) suffered from recurrent lancinating occipital pain since the age of 40 and had a history of somnambulism during childhood. She died from breast cancer at the age of 63 . According to information from cases 1-3 she was very likely to have suffered from occipital neuralgia.

One brother alive (M1953) also had suffered from a moderate headache without accompanying symptoms for migraine only in recent years probably related to arterial hypertension. On treatment with beta-blockers for hypertension he had been free of headaches for more than one year. This patient was interviewed on the phone by one of the authors (F.R.).

Three brothers of our index patient did not suffer from any pain disorders, or somnambulism.

\section{Discussion}

\section{Clinical considerations}

Cases 1-3 were considered suffering from occipital neuralgia and nervus intermedius neuralgia, although not always simultaneously. In the ICHD-II classification [7] the following diagnostic criteria are required for occipital neuralgia: (a) paroxysmal stabbing pain, with or without persistent aching between paroxysms, in the distribution(s) of the greater, lesser and/or third occipital nerves, (b) tenderness over the affected nerve and (c) pain is eased temporarily by local anaesthetic block of the nerve. Our index case clearly fulfils criteria $a$ and $b$. A local anaesthetic block of the greater occipital nerve has not been performed yet. However, success of this intervention might not be specific for occipital neuralgia, since infiltration of the greater occipital nerve is effective in primary headache disorders, such as cluster headache [8], too. Cases 2 and 3 are also very likely to suffer from occipital neuralgia, although they are less severely affected. Radiation of pain into frontal, temporal and orofacial regions, as observed in cases 1 and 2, deserves further comment. As there is evidence of more widespread headaches [9], frontal [10] and orofacial pain [11] in occipital neuralgia, our observations are consistent with this diagnosis. In this context it is noteworthy that prolonged hypaesthesia [12] has been described after greater occipital nerve block, which exemplifies convergence between cervical rootsthe origin of the greater occipital nerve-and trigeminal afferents.

The ICHD-II criteria [7] for nervus intermedius neuralgia are the following: (a) pain paroxysms of intermittent occurrence, lasting for seconds or minutes, in the depth of the ear, (b) presence of a trigger area in the posterior wall of the auditory canal and (c) not attributed to another disorder. The existence of nervus intermedius neuralgia or geniculate neuralgia as clinical entity has long been a matter of debate, since otalgia does not always originate in the nervus intermedius or the geniculate ganglion [13]. Sensory supply of the ear involves other cranial nerves, such as for instance, the glossopharyngeal nerve. A trigger zone in the auditory canal is apparent only in a minority of patients [13]. In our patients with neuralgiform pain deep in the ear, we assume that nervus intermedius neuralgia is the most accurate explanation.

Familial cranial neuralgias with involvement of two cranial nerves have been previously described, e.g., trigeminal and glossopharyngeal nerves [6]. Sensory anastomoses between cranial nerves have been described, e.g., between the facial and trigeminal nerves [14]. In addition, convergence between afferents from the intermediate nerve, descending trigeminal tracts and $\mathrm{C} 2$ roots-the origin of the greater occipital nerve-has been proposed $[13,15]$. Animal findings point towards extensive convergence of afferents from the face, teeth, neck and oral mucosa on the trigeminal nucleus caudalis [16]. Therefore peripheral sensory anastomoses or central convergence of afferent pathways could explain co-occurrence of cranial neuralgia in two nerves.

Cases of familial SUNCT (short-lasting unilateral neuralgiform headache attacks with conjunctival injection and tearing) have been described recently [17]. SUNCT can clinically resemble $\mathrm{TN}$ but has trigemino-autonomic signs such as conjunctival injection and tearing. None of our patients reported any of these signs. 
Genetic hypotheses

Considering that the father M1917 of our index patient and all his daughters (F1952, F1954 and F1944) were affected from cranial neuralgia but none of his sons (Fig. 1), an $\mathrm{X}$-linked dominant inheritance can be postulated. Alternatively, an autosomal dominant inheritance, as described in TN could be assumed. M1917 had also suffered from post-herpetic neuralgia. Recently a case report with occipital neuralgia evoked by facial herpes zoster infection was described [18] suggesting a similar trigger mechanism in this patient. Increasing age and immune suppression are well-recognised risk factors for reactivation of varicella zoster virus [19], which causes herpes zoster. About 20\% of patients with herpes zoster develop post-herpetic neuralgia and genetic susceptibility is assumed [20]. Therefore transmission of genetic vulnerability to a spectrum of neuralgic pain disorders could be postulated in our family.

Some individuals of the present family suffer from cranial neuralgia and somnambulism, or migraine. The prevalence of somnambulism in childhood was found to be elevated in patients with migraine [21] yielding speculations that both disorders might have common predisposition factors. Although no gene for sleep-walking has been found yet, substantial genetic effects are assumed [22] based on population studies. Given the comorbidity of facial neuralgia and somnambulism in this family, linkage between responsible gene loci could be postulated.

Except for autosomal dominant familial hemiplegic migraine (FHM) where several gene loci have been found, genetics of migraine is complex. The majority of genetic association studies with candidate migraine genes could not be replicated [23]. Since there is no evidence of FHM in our family, no clear hypothesis can be developed.

\section{Conclusion}

These cases present the first description of familial occipital and nervus intermedius neuralgia in a Swiss family. In some cases genetic susceptibility for cranial neuralgias seems to be important.

Conflict of interest None.

\section{References}

1. Savica R, Lagana A, Siracusano R, Calabro RS, Ferlazzo E, Musolino R (2007) Idiopathic familial trigeminal neuralgia: a case report. Neurol Sci 28:196-198
2. Smyth P, Greenough G, Stommel E (2003) Familial trigeminal neuralgia: case reports and review of the literature. Headache 43:910-915

3. Testa D, Milanese C, La Mantia L, Mastrangelo M, Crenna P, Negri S (1981) Familial trigeminal neuralgia in Charcot-MarieTooth disease. J Neurol 225:283-287

4. Coffey RJ, Fromm GH (1991) Familial trigeminal neuralgia and Charcot-Marie-Tooth neuropathy report of two families and review. Surg Neurol 35:49-53

5. Duff JM, Spinner RJ, Lindor NM, Dodick DW, Atkinson JL (1999) Familial trigeminal neuralgia and contralateral hemifacial spasm. Neurology 53:216-218

6. Knuckey NW, Gubbay SS (1979) Familial trigeminal and glossopharyngeal neuralgia. Clin Exp Neurol 16:315-319

7. The International Classification of Headache Disorders (2004) 2nd edn. Cephalalgia 24(suppl 1):9-160

8. Afridi SK, Shields KG, Bhola R, Goadsby PJ (2006) Greater occipital nerve injection in primary headache syndromes-prolonged effects from a single injection. Pain 122:126-129

9. Pascual-Leone A, Pascual-Leone Pascual A (1992) Occipital neuralgia: another benign cause of "thunderclap headache". J Neurol Neurosurg Psychiatry 55:411

10. Chouret EE (1967) The greater occipital neuralgia headache. Headache 7:33-34

11. Sulfaro MA, Gobetti JP (1995) Occipital neuralgia manifesting as orofacial pain. Oral Surg Oral Med Oral Pathol Oral Radiol Endod 80:751-755

12. Kinney MA, Wilson JL, Carmichael SW, De Ruyter ML, Fulgham JR (2003) Prolonged facial hypesthesia resulting from greater occipital nerve block. Clin Anat 16:362-365

13. Bruyn GW (1984) Nervus intermedius neuralgia (Hunt). Cephalalgia $4: 71-78$

14. Vanopdenbosch LJ, Verhoeven K, Casselman JW (2005) Bell's palsy with ipsilateral numbness. J Neurol Neurosurg Psychiatry 76:1017-1018

15. da Silva HM, Boullosa JL, Arruda MA (2006) Secondary intermedius neuralgia-like pain in a young child. Cephalalgia 26:1483-1484

16. Sessle BJ, Hu JW, Amano N, Zhong G (1986) Convergence of cutaneous, tooth pulp, visceral, neck and muscle afferents onto nociceptive and non-nociceptive neurones in trigeminal subnucleus caudalis (medullary dorsal horn) and its implications for referred pain. Pain 27:219-235

17. Gantenbein AR, Goadsby PJ (2005) Familial SUNCT. Cephalalgia 25:457-459

18. Kihara T, Shimohama S (2006) Occipital neuralgia evoked by facial herpes zoster infection. Headache 46:1590-1591

19. Sampathkumar P, Drage LA, Martin DP (2009) Herpes zoster (shingles) and postherpetic neuralgia. Mayo Clin Proc 84:274280

20. Sato M, Ohashi J, Tsuchiya N et al (2002) Association of HLA$A * 3303-B * 4403-D R B 1 * 1302$ haplotype, but not of TNFA promoter and NKp30 polymorphism, with postherpetic neuralgia (PHN) in the Japanese population. Genes Immun 3:477-481

21. Casez O, Dananchet Y, Besson G (2005) Migraine and somnambulism. Neurology 65:1334-1335

22. Hublin C, Kaprio J, Partinen M, Heikkila K, Koskenvuo M (1997) Prevalence and genetics of sleepwalking: a populationbased twin study. Neurology 48:177-181

23. de Vries B, Frants RR, Ferrari MD, van den Maagdenberg AM (2009) Molecular genetics of migraine. Hum Genet 126:115-132 